\title{
Implantable Biofuel Cells Operating In Vivo-Potential Power Sources for Bioelectronic Devices
}

\author{
Evgeny Katz \\ Department of Chemistry and Biomolecular Science, Clarkson University, Potsdam, New York, United States of America
}

\begin{abstract}
Implantable devices harvesting energy from biological sources and based on electrochemical transducers are currently receiving high attention. The energy collected from the body can be utilized to activate various microelectronic devices. This article is an overview of the recent research activity in the area of enzyme-based biofuel cells implanted in biological tissue and operating in vivo. The electrical power extracted from the biological sources presents use for activating microelectronic devices for biomedical applications. While some microelectronic devices can work within a fairly broad range of electrical operating conditions, others, such as pacemakers, require precise voltage levels and voltage regulation for correct operation. Thus, certain classes of electronic devices powered by implantable energy sources will require careful attention not only to energy and power considerations, but also to voltage scaling and regulation. This requires appropriate interfacing between the energy harvesting device and the energy consuming microelectronic device. The paper focuses on the problems in the present technology as well as offers their potential solutions. Lastly, perspectives and future applications of the implanted biofuel cells are also discussed. The considered examples include a pacemaker and a wireless signal transfer system powered by a implantable biofuel cell extracting electrical energy from biological sources.
\end{abstract}

Online address: www.bioelecmed.org

doi: 10.15424/bioelectronmed.2014.00011

\section{INTRODUCTION: BIOELECTRONICS AND IMPLANTABLE ELECTRONICS}

The scientific research and engineering in the area of implantable bioelectronic devices (1) have been progressing rapidly in the last two decades, contributing greatly to medical and technological advances, thus producing numerous applications. Additionally, this research is benefiting from novel achievements and discoveries in microelectronics, computing, biotechnology, materials science, micromachinery and many other science and technology areas. The integration of electronic elements with biological systems, resulting in novel devices with unusual functionalities, attracts significant research efforts due to the fundamental scientific interest and the possible practical applications. The commonly used buzzword "bioelectronics" highlights the functional integration of two different areas of science and engineering, biology and electronics, to yield a novel subarea of biotechnology $(2,3)$. Bioelectronics is a rapidly developing multidisciplinary research direction, combining novel achievements from electronics miniaturization allowing devices to operate with ultralow power consumption (4), the development of flexible devices for interfacing with biological tissue via advances within materials science (5), bioinspired unconventional computing for mimick-

Address correspondence to Evgeny Katz, Department of Chemistry and Biomolecular Science, Clarkson University, Potsdam, NY 13699, USA. Phone: 315-268-4421; Fax: 315-268-6610; E-mail: ekatz@clarkson.edu.

Submitted November 15, 2014; Accepted for publication December 30, 2014; Epub (www.bioelecmed.org) ahead of print January 7, 2015.

\section{The Feinstein Institute for Medical Research

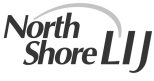
Empowering Imagination. Pioneering Discovery.

ing biological information processing (6) and many other highly innovative science and technology areas. The novel electronic systems based on flexible supports (7) for direct interfacing with biological tissues are very promising for implantable bioelectronic devices (8) (Figure 1).

The most challenging developments in bioelectronics are related to biomedical applications, particularly advancing the direct coupling of electronic devices / machines with living organisms, where electronics operate in a biological environment implanted within a living body. This technology is already highly advanced, at least in some medical applications such as implantable cardiostimulators $(9,10)$ and various other implantable prosthetic devices $(11,12)$, including vagus nerve stimulators $(13,14)$ to treat rheumatoid arthritis (15). The most important issue in the biotechnological engineering of implantable devices is the interface between living tissues and artificial manmade implantable devices.

Cardiac defibrillators/pacemakers, deep brain neurostimulators, spinal cord stim- 


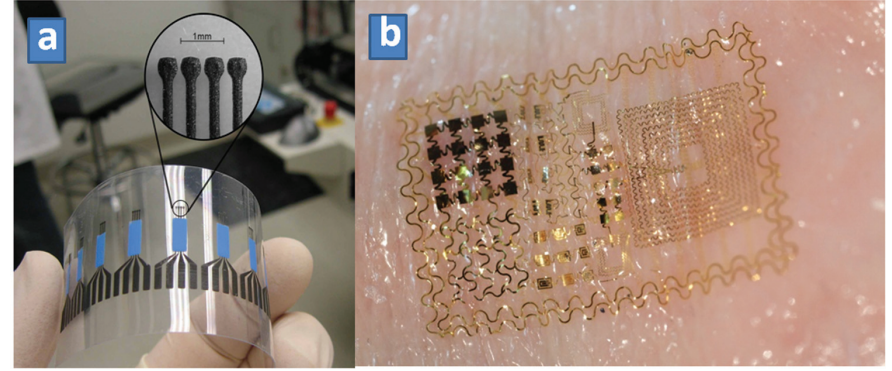

Figure 1. (a) Flexible bioelectronic devices allow interfacing with biological tissue. (b) A new type of a biosensor uses flat, flexible electronics ("tattoo" bioelectronics) printed on a thin rubbery sheet, which can stick to human skin for at least $24 \mathrm{~h}$. (Photos " $a$ " and "b" were kindly provided by Joseph Wang, University California San Diego, USA, and John A Rogers, University of Illinois at Urbana-Champaign, USA, respectively.)

ulators, gastric stimulators, foot drop implants, cochlear implants, insulin pumps, retinal implants, implantable neural electrodes, muscle implants and other implantable devices must perform their functions by directly interacting with the respective organs to improve their natural operation or substitute a missing function. The development of sophisticated implantable devices (for example, autonomously operating insulin pumps) (16) can improve the quality of life and contribute to the novel concept of personalized medicine (17). More sophisticated implantable devices, such as an artificial eye (18), currently are being designed and studied in research laboratories and will come to medical practice in the near future. Implantable medical devices also can restore function by integrating with nondamaged tissue within an organ. The artificially generated electrical and sometimes electromechanical activity in each of these cases must be engineered within the context of the physiological system and its biological characteristics. Long-term implants for different biomedical applications present specific engineering challenges related to the minimization of energy consumption, physical miniaturization and stable performance optimization. The successful integration of machines with biological systems requires energy sources harvesting power directly from physiological processes $(19,20)$ to unify the energy supply for biological and electronic/mechanical parts of the integrated system.

\section{HARVESTING POWER FROM BIOLOGICAL SOURCES-IMPLANTABLE BIOFUEL CELLS}

Harvesting power from living species $(21,22)$ including the human body $(19,23-25)$ using a broad variety of physical and chemical methods $(19,26)$ has recently attracted significant attention. Physical methods of energy harvesting from living species often employ transducers utilizing mechanical energy (27): muscle stretching (28), arm/leg swings (19), walking/running $(19,29,30)$, heart beats $(31,32)$, blood flow $(26)$, gas flow due to respiration $(19,31,33)$ and so on. Different thermoelectric (19), and piezoelectric (19) effects also can be used for energy harvesting from a living body. It should be noted, however, that all physical energy conversion methods are based on complex machinery and represent an engineering rather than a biological approach. They are highly dependent on the human/animal physical activity and conditions of the environment. Methods based on the internal physiological activity rather than physical/mechanical activity should be much more reliable for energy harvesting due to relatively stable physiological conditions in a living body. Implanted devices used for electrical power generation based on biological inspiration are the most biocompatible and promising. These systems include biolog- ical potential gradients (34) or interfacial electron transfer processes (that is, redox reactions) (35). Natural biological elements, usually enzymes, interfaced with electrodes in implantable bioelectrochemical systems, typically biofuel cells (36-38), have illustrated significant importance.

Biofuel cells (39) that extract electrical energy by oxidizing biomolecules have been developed based on the biocatalytic activity of enzymes (40-49). Despite the fact that implantable biofuel cells operating in vivo had been suggested a long time ago (50), they are still exotic, and highly challenging to design, bioelectronic systems. While potentially implantable biofuel cells have been discussed, in reality, most of the experiments were performed in model solutions (51-53) or at best in human serum or blood in vitro $(54,55)$. A few examples of fuel cells and biosensors operating in vivo being implanted in living organisms were published already in the 1970s, however, this research was not extensively continued because of many scientific and engineering problems which were not possible to address at that technology level. This research direction was reborn in the 2010s when new approaches to the efficient bioelectrocatalytic processes became possible (56) (Figure 2). Significant breakthrough has been achieved in the last three years with several papers reporting implanted biofuel cells operating in vivo in living animals: insects (57), mollusks (snail and clams) (58,59), lobsters (60) (Figure 3), rats (61-65) (Figure 4) and rabbits (66). The implanted biofuel cells generated electrical power by enzyme-modified electrodes, utilizing physiologically produced "fuel" and oxygen already abundant in biofluids. Typically, glucose was used as the "fuel" in the freely circulating hemolymph of invertebrates (snails, clams, lobsters) (58-60) and in the blood vessels of vertebrate animals (rats, rabbits) (61-66).

Despite the fact that enzyme-based biofuel cells progressed a lot in the last 20 years, reaching the state where the electrodes operate in vivo being implanted in 


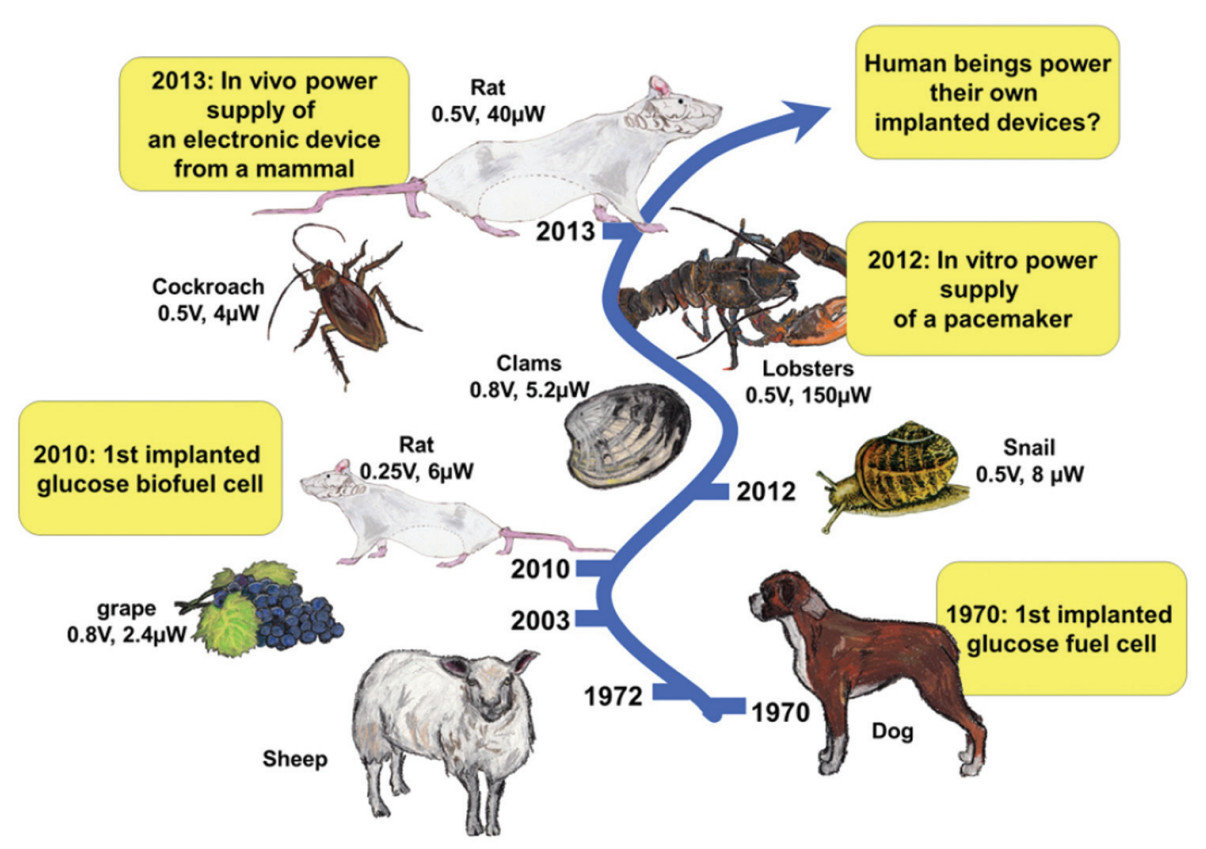

Figure 2. The timeline of development of implanted biofuel cells/biosensors operating in vivo in living organisms. Note that in the early devices the catalytic electrodes were based on inorganic materials, while later enzyme-based electrodes became available for the in vivo operation. (The scheme is adopted from reference (56) with permission.)

living organisms, the motivation for their design is not always clear. In most of the published papers, the authors claim their use as a source of sustainable power extracted from renewable biological resources, while some of the researchers emphasize their specific operation as implantable devices providing power for biomedical electronic implants. It is obviously naïve to believe that enzyme-based systems will ever produce cheap and large enough electrical power for electrical or electromechanical devices in households or industry. From the very beginning of their developments, biofuel cells were considered as potential sources of microscale power for biomedical use while operating in the biological environment being implanted in biological tissue $(67,68)$. Famous schematics of a biofuel cell implanted in a blood vessel and extracting electrical power from oxidation of glucose present in blood was suggested by Adam Heller as early as the 1990s (Figure 5). However, this design was not yet realized because of numerous scientific and technological problems. In sources have been discussed in the literature, most of the research results are lim-

some recent publications, nanoscale biofuel cells have been suggested for harvesting nanopower from biological sources (35). While numerous speculative/futuristic suggestions for practical use of nano-/micropower implantable most of the research results are limpermission of the Royal Society of Chemistry.) ited to the measurements of the produced power, optimization of bioelectrocatalytic processes and increasing the lifetime of the biofuel cells with no specific emphasis on their practical applications. One of the recent examples of such research (58) is shown in Figure 6. Electrodes modified with enzymes biocatalytically oxidizing glucose and reducing oxygen were studied by cyclic voltammetry to demonstrate the bioelectrocatalytic processes and evaluate the potential difference produced by the cathodic and anodic processes. Upon recording cyclic voltammograms for the PQQ-GDH-electrode (PQQ-dependent glucose dehydrogenase; E.C. 1.1.5.2), the anodic current corresponding to the bioelectrocatalytic glucose oxidation was developed at the potentials more positive than $-0.1 \mathrm{~V}$ (versus Ag/AgCl) (Figure 6a). The cyclic voltammograms obtained for the laccase-modified electrode (laccase is an oxygen reducing enzyme, E.C. 1.10.3.2) demonstrated the cathodic bioelectrocatalytic current corresponding to the oxygen reduction starting at $0.6 \mathrm{~V}$ (Figure $6 \mathrm{~b}$ ) thus allowing about $700 \mathrm{mV}$ potential difference between the anodic and cathodic reactions. The biocatalytic electrodes were implanted in a snail (Neohelix albolabris) (Figure 6c) and current-voltage characteristics of the biofuel cell were obtained for a variable load resistance (Figure 7). The maximum power, $\mathrm{P}_{\max }$ pro-

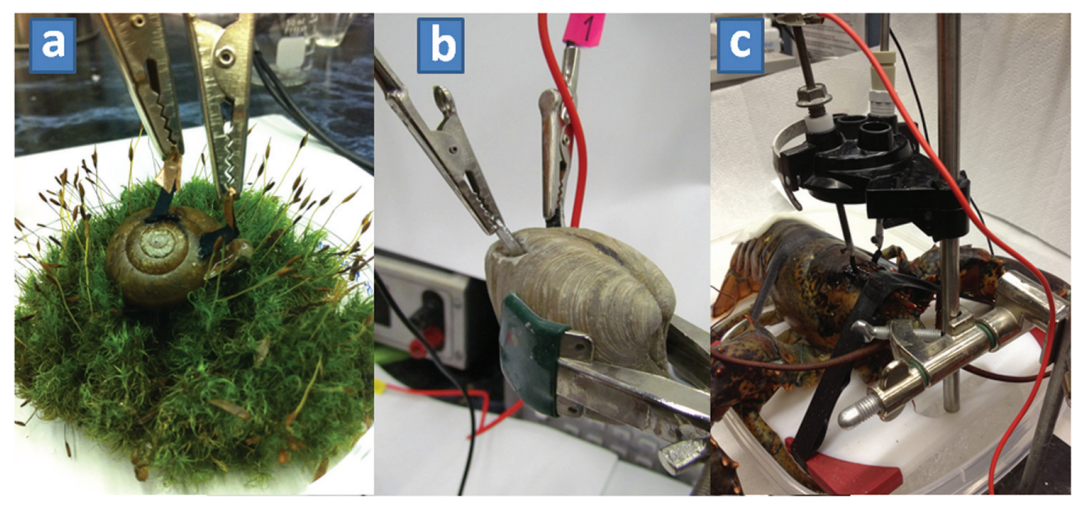

Figure 3. Implanted biofuel cells for operating in vivo in invertebrates: (a) snail, Neohelix albolabris; (b) clam, Mercenaria mercenaria; and (c) lobster (Homarus americanus). (Part " $a$ " is adapted from reference (58) with permission, copyright American Chemical Society, 2012; parts " $b$ " and " $c$ " are adapted from references $(59,60)$, reproduced with the 

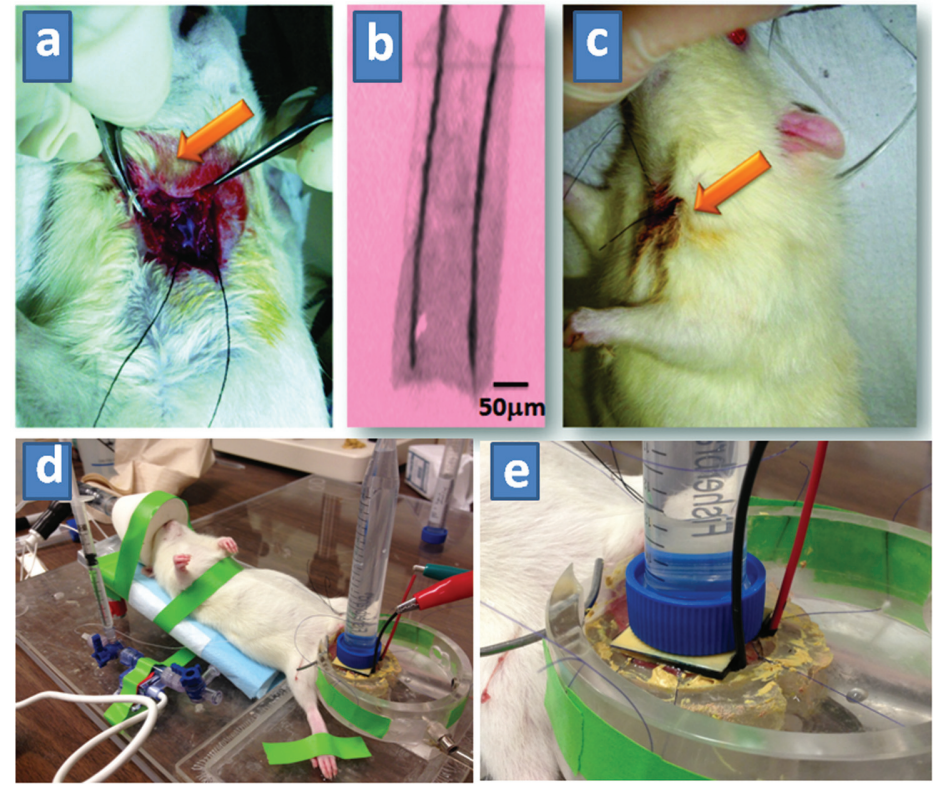

Figure 4. Implanted biofuel cells operating in vivo in rats: (a) a photograph of the catheter implanted into the jugular vein of a rat (Rattus norvegicus) for use as a glucose $/ \mathrm{O}_{2}$ biofuel cell, (b) an optical microscope image of the enzyme-modified electrodes inside the catheter, (c) the catheter surgically introduced at the ventral surface of the living rat, (d) a rat (Sprague Dawley) with the cremaster tissue surgically exposed to enzyme-modified biocatalytic electrodes, $(e)$ the cremaster tissue exposed to the biocatalytic electrodes (close view). (Parts " $a-c$ " are adapted from reference (62) with permission of the Royal Society of Chemistry; parts " $d-e$ " are adapted from reference (65), with permission.)

duced by the implanted biofuel cell on the optimum resistance, $20 \mathrm{k} \Omega$ (equal to the internal resistance of the implanted cell), was $7.45 \mu \mathrm{W}$ (power density ca. $30 \mu \mathrm{W} \cdot \mathrm{cm}^{-2}$ ) (Figure 7, inset). The current produced by the implanted biocatalytic electrodes rapidly decreased due to slow glucose diffusion through the viscous biological medium; however, it was restored when the electrodes were disconnected and glucose diffused to their surfaces. The most impressive was the observation that the electrical output produced by the implanted biofuel cell increased upon feeding the snail, thus confirming that it is indeed proportional to the physiological concentration of glucose in hemolymph (snail's analog of blood) (Figure 6d). While the reported results are scientifically novel and interesting, particularly due to the biofuel cell operation in vivo, the practical applicability of the produced power is still questionable.

\section{INTERFACING IMPLANTED BIOFUEL CELLS WITH BIOMEDICAL MICROELECTRONIC DEVICES}

Despite the fact that many papers demonstrated power release from biofuel cells, which may potentially be enough for activating electronic devices, real interfacing of electronics with implanted biofuel cells was limited to very few examples. The major problem is the low voltage produced by biofuel cells, which is thermodynamically limited by the redox potentials of the biological fuel (usually glucose) and oxygen. In most of the reported biofuel cells the open circuit voltage hardly exceeds $0.5 \mathrm{~V}$ being decreased upon consuming current from the cells (39-41); at best the voltage was measured as high as $0.78 \mathrm{~V}$ while operating under nonphysiological conditions (69). However, this voltage is still not enough for most electronic devices, which usually require several volts for their operation. Improving efficiency of biofuel cells includes mostly increasing their current production and results in a very little effect on the voltage, which is thermodynamically limited. It should be noted that most papers on biofuel cells do not discuss the problem of their interfacing with electronics, but remain concentrated on resolving internal problems of the biofuel cells, such as current efficiency, stability and so on. Two approaches have been applied to resolve the low voltage problem: (i) assembling biofuel cells in series electrically, thus increasing the total output voltage (59,70-72), and (ii) collecting produced electrical energy in capacitors/charge pumps for the burst release in short pulses (73-76). The latter approach has already been applied for activating a wireless transmitting electronic device, however using nonimplantable enzymebased $(76,77)$ or microbial biofuel cells (73). These approaches, particularly as used with implantable enzyme-based biofuel cells, will be exemplified and discussed below.

The first approach, based on stacking biofuel cells, increasing the output voltage upon their serial connection, can be illustrated by the biofuel cells implanted in living lobsters (Homarus americanus)

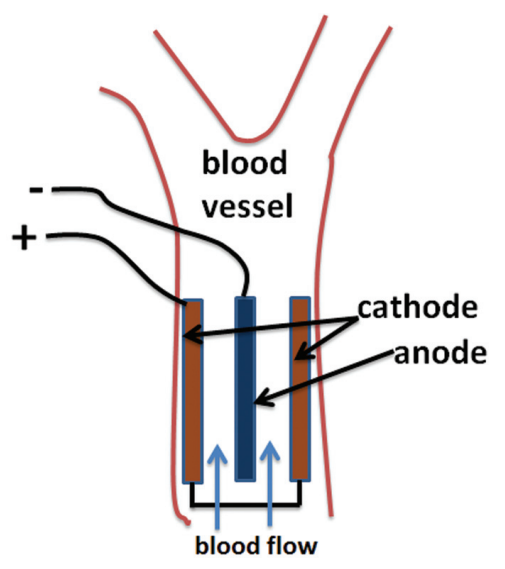

Figure 5. Schematic futuristic vision of a biofuel cell implanted in a blood vessel for extracting electrical power by oxidation of glucose.This schematics was suggested by Adam Heller as early as in the 1990s, and similar images are shown in numerous websites. 


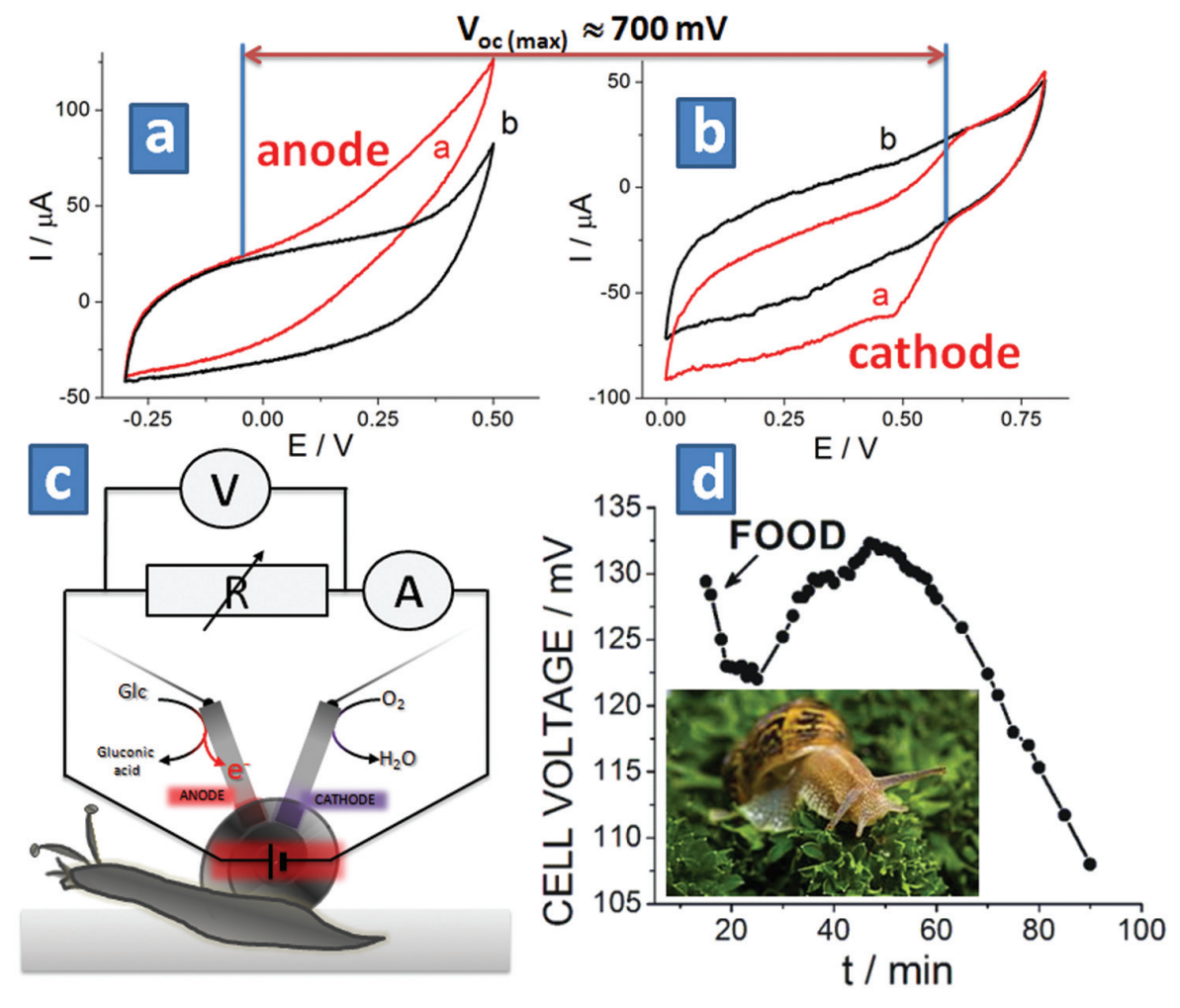

Figure 6. A biofuel cell implanted in a snail: (a) cyclic voltammograms of the PQQ-GDHanode: curves $b$ and $a$ were obtained in the absence and presence of $20 \mathrm{mmol} / \mathrm{L}$ glucose, respectively; (b) cyclic voltammograms of the laccase-cathode: curves b and a were obtained in the absence and presence of $\mathrm{O}_{2}$, respectively. All cyclic voltammograms were obtained in vitro in a buffer solution, $\mathrm{pH} 7.4$, scan rate $1 \mathrm{mV} \cdot \mathrm{s}^{-1}$; (c) the electrical circuitry including a biofuel cell implanted in a snail and connected to a variable load resistance; (d) variation of the voltage produced by the biofuel cell in vivo in real time upon feeding the snail. (Parts " $a-c$ " are adapted from reference (58) with permission, copyright American Chemical Society, 2012.)

(60). A single pair of the biocatalytic electrodes, PQQ-GDH-anode and laccasecathode on the buckypaper conductive support (buckypaper is the composite material made of compressed multiwalled carbon nanotubes), were implanted in lobster tissue in contact with hemolymph containing glucose and oxygen. The biofuel cell was connected to a variable load resistance, producing the voltage and current (Figure 8a). In a typical experiment, open circuit voltage, $\mathrm{V}_{\mathrm{oc}^{\prime}}$ and short circuit current, $\mathrm{I}_{\mathrm{sc}^{\prime}}$ achieved in the biofuel cell in vivo were ca. $550 \mathrm{mV}$ and ca. $1 \mathrm{~mA}$, respectively. The maximum power, $\mathrm{P}_{\text {max }}$, produced in the typical experiment by the implanted biofuel cell at the optimum resistance of $500 \Omega$ was ca. $0.16 \mathrm{~mW}$. While the generated power might be enough for activating some low-power microelectronic devices, the voltage output was obviously below the threshold required by electronics. To increase the voltage, two pairs of the biocatalytic electrodes were implanted in lobster's tissue and connected in series (Figure 8b). The result was quite disappointing; the series connection of two biofuel cells showed only a minor (50 to $100 \mathrm{mV}$ ) increase in the produced voltage, falling markedly short of the expected doubled voltage. This negative experimental result was easily explained by the low internal electrical resistance of the lobster's body tissue, $\mathrm{R}_{\mathrm{T}}$ (the resistance between the electrodes implanted in the lobster's back at a distance of $2 \mathrm{~cm}$ was ca. $180 \mathrm{k} \Omega$ ), which formed a low impedance path (jumper) between the anodes and cathodes (Figure 8c), thus preventing the desired operation of the two fuel cells in series. To resolve the problem, two biofuel cells were implanted in two different lobsters and then connected in series (Figure 8d). In this configuration the voltage output doubled, as expected, producing enough electrical energy to successfully activate and consistently power an electronic watch, intended as a "proof-of-concept" electronic load with the minimum required voltage of ca. $1 \mathrm{~V}$ (Figure 9). While connecting more living lobsters with implanted biofuel cells is possible, further augmentation of the voltage by the connection of additional lobsters to the circuit is impractical. Therefore, the next set of experiments moved to the in vitro model system. Again, as was demonstrated with two biofuel cells implanted in the same lobster, two pairs of biocatalytic electrodes immersed in the same solution do not produce drastically increased output voltage when the electrodes are connected in series (Figure 8e). Therefore, five separate flow biofuel cells filled with human serum solution, mimicking the human circulatory system, were connected in series (Figure 8f) resulting in a voltage output increase up to ca. $3 \mathrm{~V}$, which was already enough to activate most microelectronic devices. Note that the biofuel cells were connected to separate flow pathways to prevent electrical shortcut connections between the electrodes. To illustrate the interfacing of the biofuel flow cells with an implantable biomedical device, a pacemaker (Affinity DR 5330L; St. Jude Medical Inc., St. Paul, MN, USA) was selected as an example (60). A sealed pacemaker was cut open and the internal battery was removed, allowing the pacemaker to be wired to the external biofuel cell (Figure 10a). When the pacemaker was connected to the biofuel flow cell (Figure 8f) it started to generate pulses, as expected. The pulses being registered by the oscilloscope demonstrated voltage spikes of ca. $5 \mathrm{~V}$ 


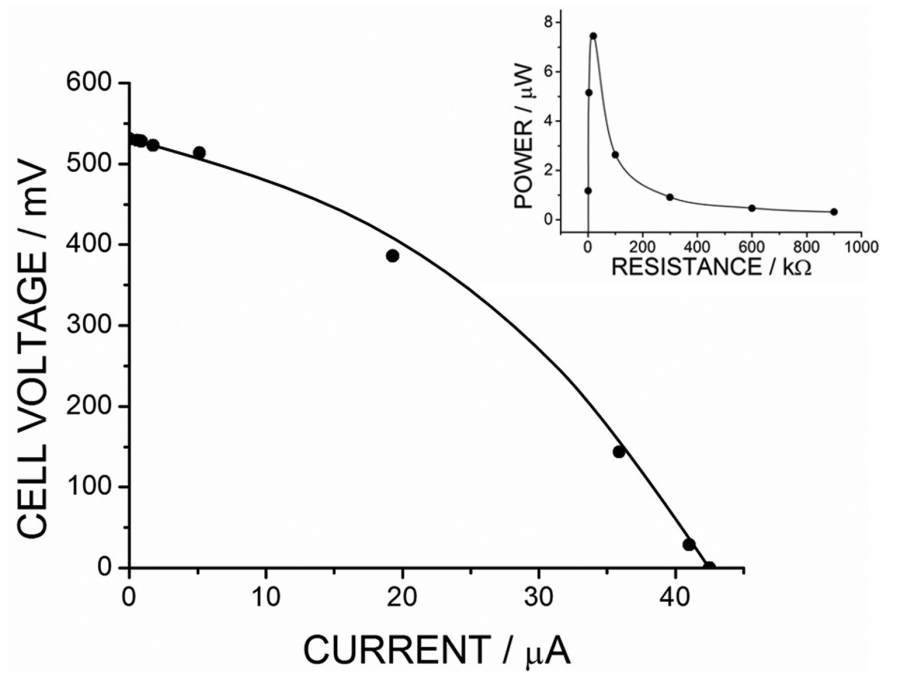

Figure 7. Polarization curve of the biofuel cell implanted in a snail and operated in vivo. Inset: Power generated on a variable load resistance. (Adapted from reference (58) with permission, copyright American Chemical Society, 2012.)

with the duration of ca. $0.6 \mathrm{~ms}$, separated by the time gaps of ca. $1 \mathrm{~s}$, indicative of normal pacemaker performance (Figure 10b). Particularly important was that the shape of the generated pulses was characteristic of the normal behavior of the pacemaker (10). The present result, while being the very first to activate a pacemaker by a biofuel cell mimicking the human circulation system, is still very disappointing and impractical; the power was extracted from five independently working biofuel cells connected to separate fluidic channels. In other words, translating this approach to real-world applications, five people with an implanted biofuel cell, connected together with wires, could activate only one implanted pacemaker. Note that five biofuel cells cannot increase the voltage if they are implanted in the same body, as was shown with lobsters and flow cells. Therefore, this approach cannot be practically useful, at least for the implantable biofuel cells.

The second approach based on electronic interface devices such as charge pumps and other forms of DC-DC convertors has already been applied for the activation of a wireless transmitting electronic device; however, using nonimplantable enzyme-based $(76,77)$ or micro- bial biofuel cells (73). The application of an interface device to increase the voltage is rather well-known (78), however it should be remembered that the voltage increase is achieved at the expense of the current consumed by the charge pump, thus putting additional demand on the current output of the biofuel cell. Implantable microsize electrical energy generators connected to an electrical interface can be used effectively for activating microelectronic devices operating in the short-pulses regime, using the time between pulses for the accumulation of energy (34). However, an implantable biofuel cell connected to a charge pump and used for the continuous operation of implantable biomedical devices, for example, a pacemaker, requires constant current production sufficient to keep the device continuously running. To satisfy the high current demand for the operation of the charge pump, large biocatalytic electrodes (buckypaper with a geometric area of $6 \mathrm{~cm}^{2}$ ) modified with PQQ-GDH on the anode, and laccase on the cathode, were used in a biofuel cell filled with human serum solution and operating under conditions mimicking human physiological bloodflow (79). The biofuel cell was connected to a variable load resistance and polarization was measured, demonstrating the open circuitry voltage, $\mathrm{V}_{\mathrm{oc}}$ ca. $470 \mathrm{mV}$ and short circuitry current, $\mathrm{I}_{\mathrm{sc}^{\prime}}$ ca. $5 \mathrm{~mA}$. The biofuel cell mimicking an implantable device was connected to the charge pump and DC-DC converter interface circuit, which was further connected to a pacemaker (Figure 10c). To analyze the pacemaker performance, the pacemaker output leads were connected to an implantable loop recorder (ILR), a subcutaneous electrocardiographic (ECG) monitoring device. In the present setup, it was used as a medically relevant analyzer of the electrical pulses produced by the pacemaker receiving the power from the biofuel cell. The loop recorder output was read wirelessly by the sensor device of the Medtronic CareLink Programmer, Model 2090 (Medtronic, Minneapolis, $\mathrm{MN}, \mathrm{USA}$ ), typically used for the programming and maintenance of pacemakers and loop recorders after implantation (80). Two borderline indistinguishable functions were generated by the ILR upon registering the electrical pulses produced by the pacemaker: one from the pacemaker powered by a standard battery, and one from the pacemaker powered by the implantable biofuel cell. The profound similarities in these two results confirm the correct pacemaker operation while receiving power from the external biofuel cell through the charge pump and DC-DC converter interface circuit. This approach for powering the pacemaker using a single biofuel cell is already practically applicable for future biomedical applications. Still additional research and engineering are necessary to solve remaining major problems. The biocatalytic electrodes presently used in the fluidic system operating in vitro are too large to be implanted in a human body, thus current efficiency should be increased to allow for smaller electrodes.

The issue of the small current, insufficient for the continuous operation of charge pumps, should be discussed further because many papers are reporting on micro- or even nano-size electrodes (35). Indeed, when the biocatalytic elec- 
a

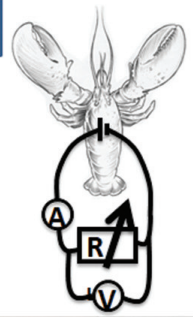

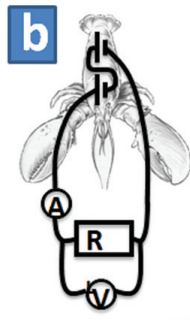
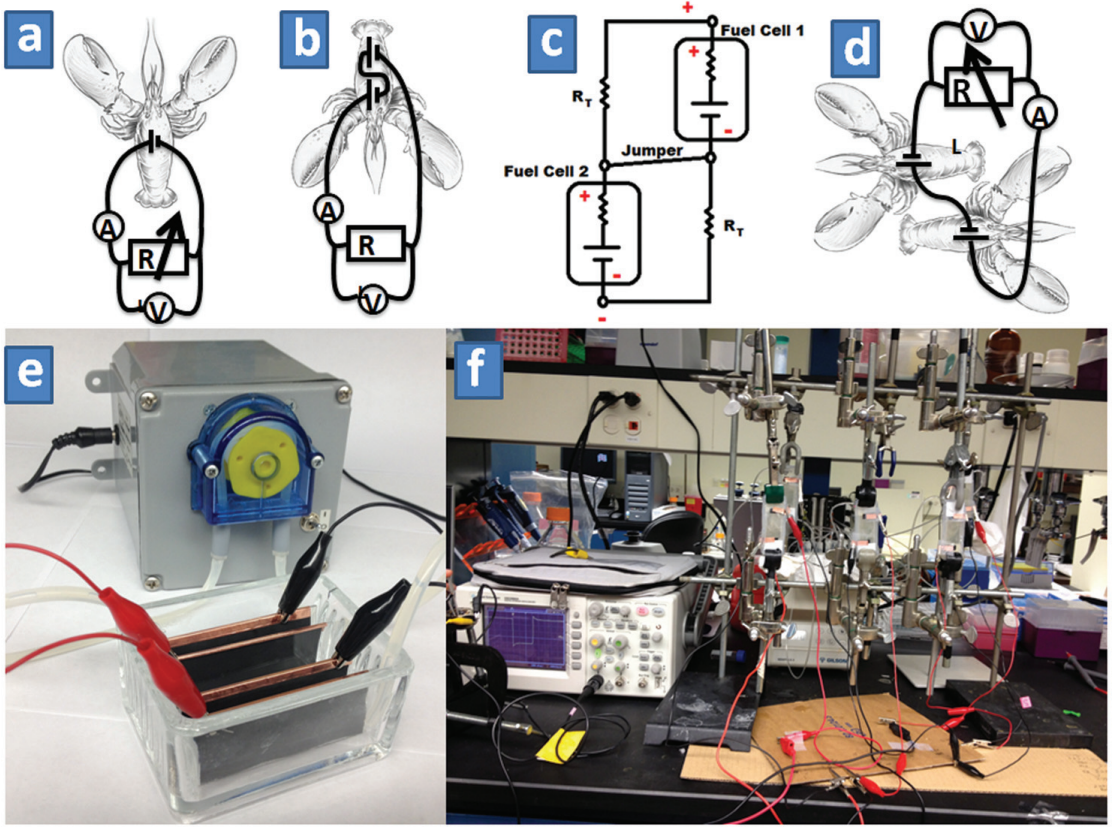

Figure 8. (a-d) The cartoons showing schematically different wirings of the biocatalytic electrodes implanted in lobsters: (a) a single pair of the biocatalytic cathode-anode electrodes implanted in the lobster; (b) two pairs of the biocatalytic cathodes-anodes implanted into the same lobster and connected in series; (c) the electrical circuitry equivalent to the wiring scheme shown in (b); (d) two pairs of the biocatalytic cathodes-anodes implanted into two different lobsters and connected in series. (e) A flow biofuel cell with two pairs of the biocatalytic electrodes immersed in the same solution and connected in series. (f) The setup composed of five separate flow biofuel cells used for powering the pacemaker (three biofuel cells are well visible in the front row, while two other biofuel cells are only partially visible in the back row). (Parts " $a-d$ " and " $f$ " are adapted from reference (60), reproduced with permission of the Royal Society of Chemistry.)

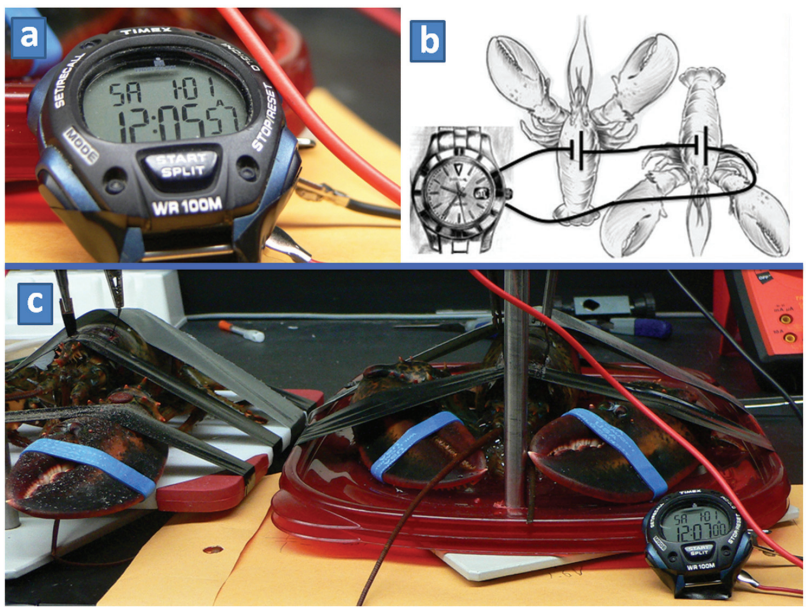

Figure 9. The biofuel cells composed of two pairs of the biocatalytic cathodes-anodes implanted in two lobsters wired in series and used for powering an electronic watch.

(a) The operating watch powered by the implanted biofuel cells; (b) the wiring scheme;

(c) the photo of the setup. (The figure is adapted from reference (60), reproduced with permission of the Royal Society of Chemistry.) trodes are implanted in small animals (rats, rabbits) (61-66) or even insects (57) their size is rather small (some electrodes have micro- or even nano-size dimensions). For very small electrodes, even if their operation is very efficient and the generated current density is large, the total current produced will be small and likely insufficient for continuous operation of microelectronic devices interfaced through the charge pump. In some cases, these nanosized electrodes may not produce enough current to power even the charge pump itself, let alone any additional microelectronics. Figure 11 shows the polarization functions of various implanted/implantable biofuel cells, as well as the demand curve of the charge pump used for activating the pacemaker. The low voltage generated by the biofuel cell can be increased with the help of the charge pump only if the current supplied by the cell to the charge pump is above a certain threshold value. In the present plot, it is represented by any polarization curve of the biofuel cells positioned above the demand I-V curve of the charge pump. It is very clear that only the large size electrodes operating in vitro satisfy the current demand of the charge pump, while the biofuel cells implanted in snails, rabbits and rats do not provide enough current to activate the charge pump for the continuous powering of the pacemaker. This problem can be resolved by using more efficient biocatalytic electrodes as well as using more efficient charge pumps. From this, it is clear that any small implanted biofuel cells, for example, operating in insects will never satisfy the conditions required for the continuous operation of microelectronic devices. One circumstance where these small-size biofuel cells may still prove useful is for devices activated for a short time, with significant time gapes between their active states, thus allowing accumulation of the electrical energy for the burst release.

It should be noted that the original futuristic vision for the in vivo operation of biofuel cells suggested their location inside a blood vessel (67) (Figure 5) thus 


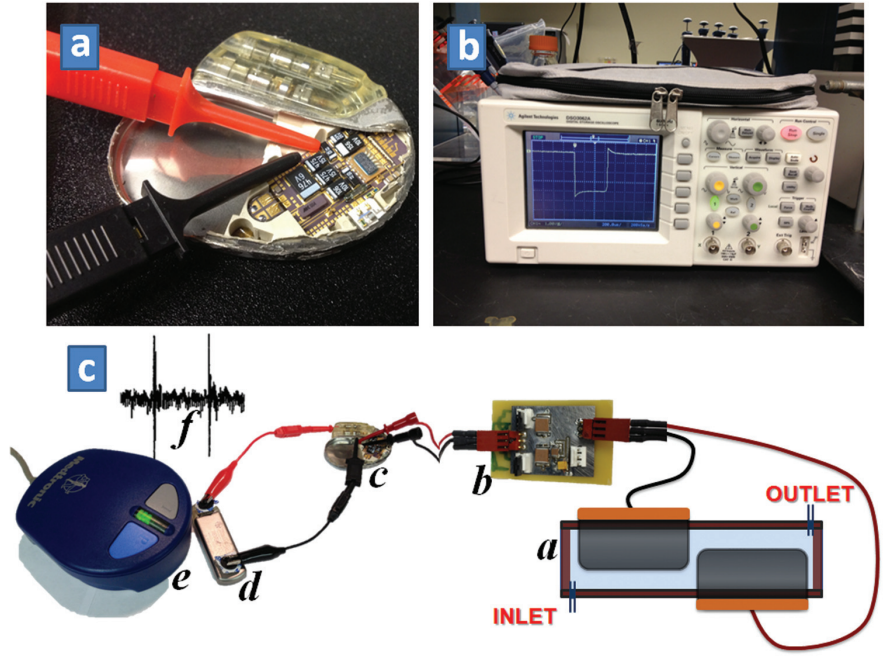

Figure 10. (a) Open pacemaker-a close view showing the microscheme and wiring leads connected to the external power source. Note the empty space (left part of the device) from which the original battery was removed. (b) Oscilloscope measuring the electrical pulses produced by the pacemaker activated by the biofuel cell. (c) Experimental setup including (from right to left): (a) the biofuel flow cell with the inlet/outlet connected to a peristaltic pump (not shown in the scheme); (b) the charge pump-DCDC interface circuit; (c) Affinity DR 5330L, St. Jude Medical, pacemaker; (d) Medtronic Reveal XT, Model 9529, implantable loop recorder (ILR); (e) sensor device for the Medtronic CareLink Programmer, Model 2090; and ( $f$ ) registered pulses generated by the pacemaker powered by the biofuel cell. (Part " $c$ " is adapted from reference (79), reproduced with permission of the Royal Society of Chemistry.)

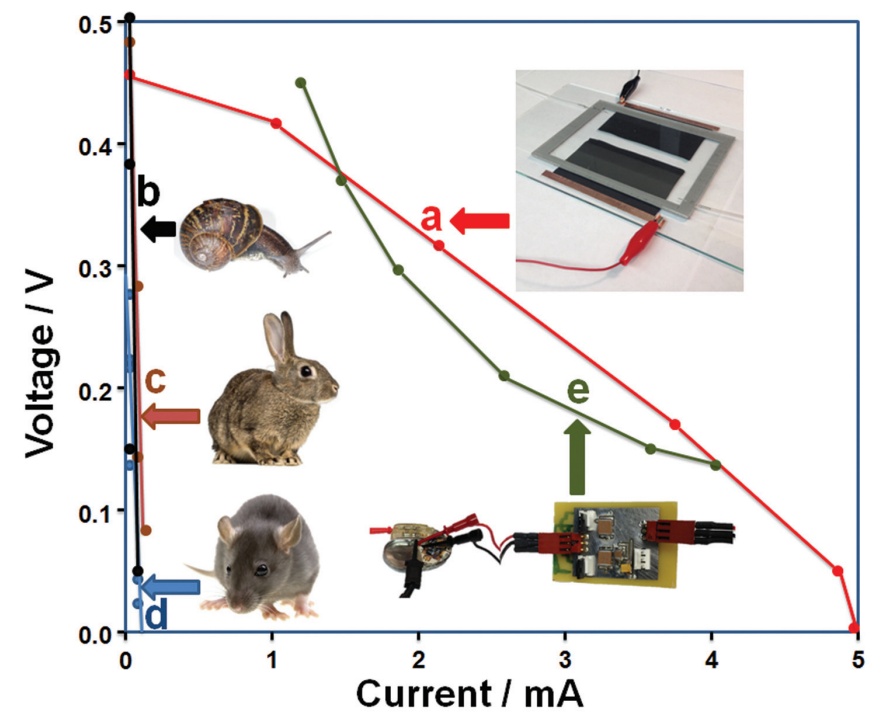

Figure 11. Polarization curves of the biofuel cells measured on the variable resistances, voltage and current produced by the cell as the function of the Ohmic resistance load: (a) an implantable biofuel cell operating in vitro in a flow device filled with a human serum solution (79); (b) a biofuel cell implanted in a snail and operating in vivo (58); (c) a biofuel cell implanted in a rabbit and operating in vivo (66); (d) a biofuel cell implanted in a rat and operating in vivo (61); and (e) I-V curve characterizing the operation of a charge pump interfaced with a pacemaker (79). Curves " $c$ " and " $d$ " were recalculated from the data available in the original publications. microfluidic biofuel cells were the original conceptual model of implanted biofuel cells (81) assuming small size of the implanted electrodes. However, larger electrodes could be simply deposited on the surface of the tissue where blood within the capillary bed supplied glucose and oxygen to the electrodes as it naturally supplied nutrients to the tissue. While being not limited by the blood capillary size, the larger electrodes could potentially generate higher current. This approach was demonstrated recently on the rat cremaster muscle where the biocatalytic electrodes were supplied with glucose and oxygen from the tissue (65) (Figures 4d, e). Another approach resulted in the design of "tattoo" biocatalytic electrodes externally located on a human body (82) and assembled in wearable biofuel cells extracting energy from externally accessible human biofluids, such as saliva or sweat, containing different biofuels, for example, lactate (83) (Figure 12). The external location of the biocatalytic electrodes allows their larger size, not limited by a blood vessel, thus allowing higher power production. Also many other issues of biocompatibility can be easier satisfied for the externally located electrodes.

The issue of the small current insufficient for the continuous operation of bioelectronic devices such as pacemakers might be not important for powering electronic devices switchable in the active mode only for a short time with relatively long periods of time in a sleeping mode. One exceptional example of such interfacing of the implanted biofuel cell with electronic devices for their short-time activation was reported recently (64). The biofuel cell was implanted in the abdominal cavity of a rat, with the wiring to the external devices organized on the head of the animal (Figure 13). The biofuel cell electrical output was interfaced with an ultra-low power boost converter (another kind of a charge pump allowing accumulation and release of the electrical energy in short pulses) and then connected to a light-emitting diode (LED) or a digital thermometer as example electronic de- 


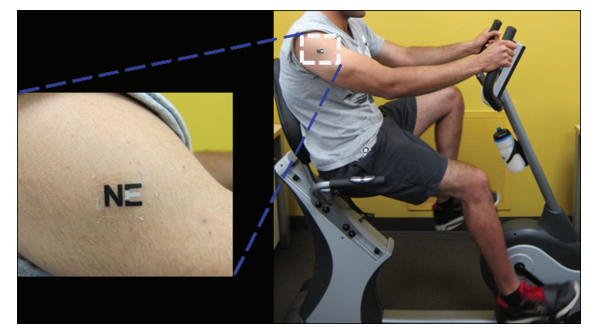

Figure 12. Electrochemical tattoo biosensor for real-time noninvasive lactate monitoring during fitness activity. Similar externally located biocatalytic electrodes can be used for assembling wearable biofuel cells producing electrical power extracted from external biofluids, for example, sweat. (The image was kindly provided by Joseph Wang, University California San Diego, USA.)

vices. The system allowed flashes of the LED and thermometer operation after periods of energy accumulation by the boost converter. This technology cannot be applied for activating biomedical devices requiring continuous power supply, for example, pacemakers (note that even though pacemakers produce short electrical pulses, they must be continuously electrically active) $(9,10)$. However, it might be sufficient for biosensing and data transmitting when the electronic devices operate in short periods of time separated by mute time periods, allowing for the accumulation of electrical energy. Additionally, this approach could potentially be used for activating implantable medical biosensing devises, monitoring physiological parameters and periodically transmitting the data. For example, enzyme-based biocatalytic electrodes oxidizing glucose and fructose were implanted in an orange and the in situ-produced electrical power was used to activate a wireless transmitting device (84) (Figure 14). The voltage management was organized with a charge pump and energy was accumulated in a capacitor until the voltage reached the threshold value required by the transmitting module. The wireless signal transmission powered by the biofuel cell implanted in the orange was performed in short pulses separated

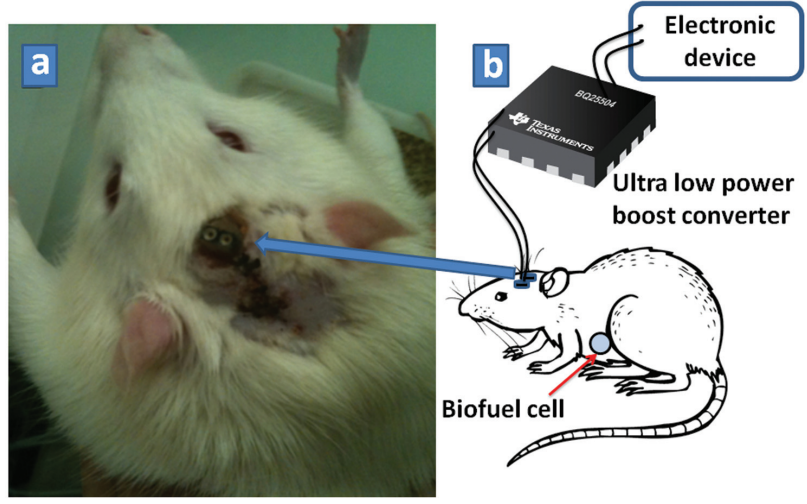

Figure 13. A biofuel cell implanted in the abdominal cavity of a rat and interfaced with a voltage boost converter for increasing the output voltage to activate external electronic devices: (a) electrical connection of the biofuel cell implanted in a rat (the output wires are fixed to the rat's skull); (b) the wiring scheme. (Part " $a$ " is adapted from reference (64), with permission.) by long time periods when the system accumulated energy.

Another important problem, which should be resolved prior to real biomedical applications of implantable biofuel cells, is the stability of such cells. The biofuel cells presently used for activating pacemakers can operate for hours, at best for several days, while the current batteries operating as electrical power supplies for pacemakers provide power for at least 10 years $(9,10)$. Therefore, implanted biofuel cells will be competitive with the presently used batteries only if
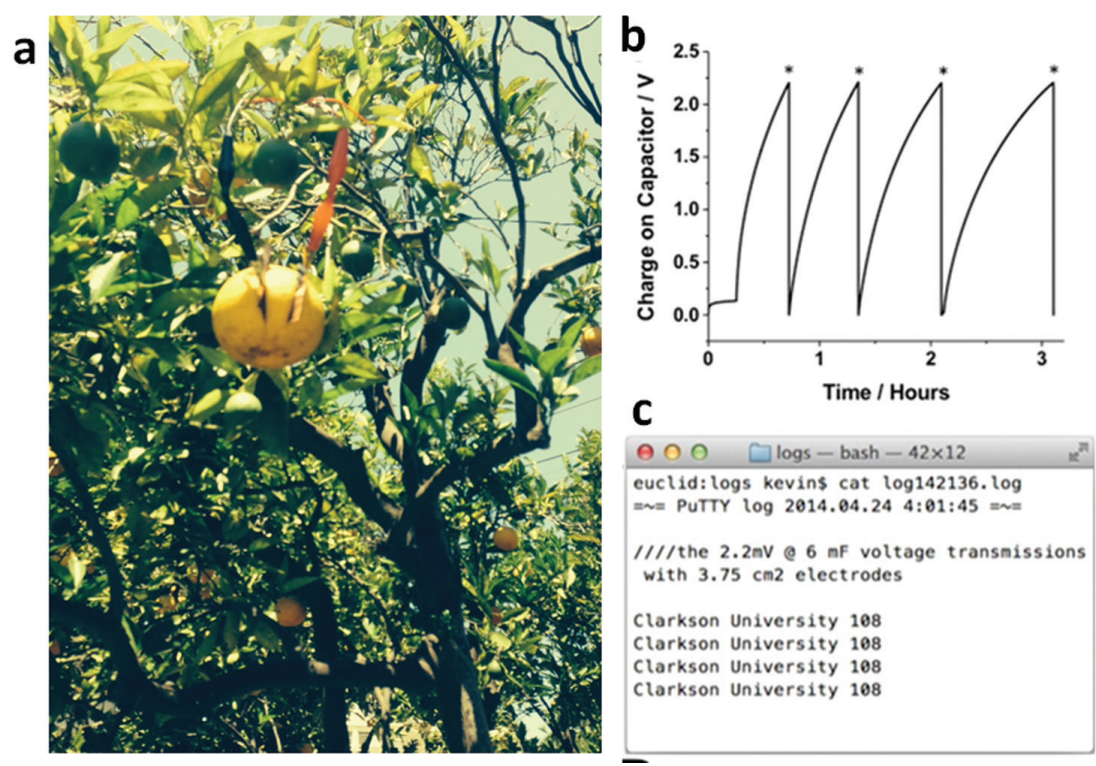

Figure 14. (a) The orange tree with an orange containing the implanted biocatalytic electrodes. (b) Voltage variations of the supercapacitor upon charging by the biofuel cell implanted in an orange. The asterisks show the time when the voltage reached the value required for activation of the transmitting device and the actual transmission was performed. (c) The wireless transmitted message "Clarkson University" read on a computer screen through the receiver operation. 


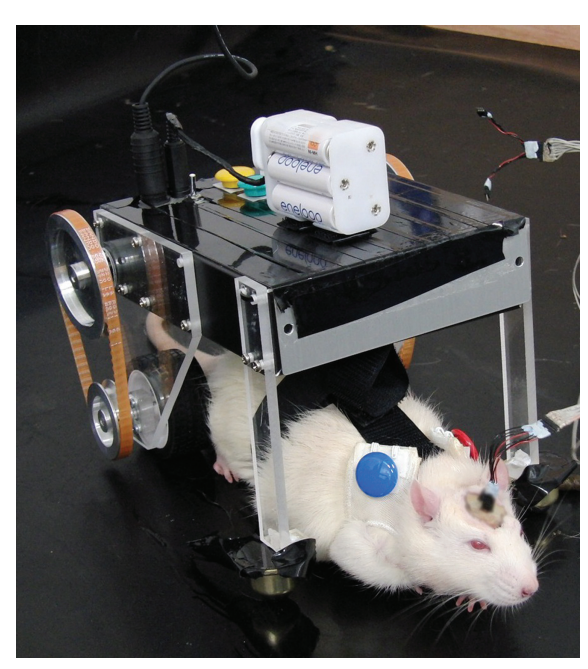

Figure 15. Brain-machine interface allowing control of moving robotic vehicles. Ratrobot hybrid involves implanted neural electrodes that allow the rat's brain signals to control a motorized vehicle. (Photo was kindly provided by Kunihiko Mabuchi and Osamu Fukayama, The University of Tokyo, Japan.)

they can operate in vivo more than 10 years, which is not achievable at the present level of technology, at least using enzyme-based biocatalytic electrodes. On the other hand, there is an alternative approach to biofuel cells, where the catalytic electrodes are modified instead with inorganic materials. These biofuel cells are called "abiotic" (85-90) and they demonstrated excellent performance (91-95), including operation in vivo $(91,96)$, to allow their competition with the enzyme-based biofuel cells. Abiotic biofuel cells also were successfully applied for activation of biomedical devices, such as pacemakers $(91,97,98)$. Abiotic biofuel cells can offer much better stability compared with the enzymebased cells, at least when they operate in clean buffer solutions. However, this advantage is not obvious for their operation in biofluids, where the high concentration of biomolecules, particularly proteins, can result in rapid inactivation of the inorganic catalytic species due to the biomolecular adsorption. Also, the inorganic species do not have high selectivity for catalyzing redox reactions char- acteristic of enzymes. Thus, the anodic oxidation of glucose may interfere with the reduction of oxygen on the same electrode and vice versa, resulting in a decrease in the voltage generated by the cell.

\section{CONCLUSIONS AND PERSPECTIVES}

Rapid progress in science and engineering has made possible and commercially available many implantable biomedical devices, including pacemakers (9), deep brain neurostimulators (99), spinal cord stimulators (100) and others, improving natural operation or substituting a missing function of a human body. The development of sophisticated implantable devices, for example, autonomously operating insulin pumps (16), can improve the quality of life and contribute to the novel concept of personalized medicine (17). Long-term implants for different biomedical applications present specific engineering challenges related to the minimization of energy consumption, physical miniaturization and stable performance optimization. The successful integration of machines with biological systems requires energy sources harvesting power directly from physiological processes (19) to unify the energy supply for biological and electronic/mechanical parts of the integrated system. The design of implanted biofuel cells (38) operating in vivo promises for future various medical electronic implants powered by implanted biofuel cells and resulting in bionic human-machine hybrids (101). Aside from biomedical applications, one can foresee bioelectronic self-powered "cyborgs" (102) based on various animals (Figure 15) which can operate autonomously using power from biological sources and used for environmental monitoring, homeland security and military applications. In all bioelectronic systems, regardless their applications and complexity, the power sources will be highly important, and implanted biofuel cell are promising devices for providing electrical power extracted from the internal physiological resources.

\section{ACKNOWLEDGMENTS}

This work at Clarkson University was supported by the NSF award \# CBET-1066397.

Notes: (a) Research on animals was approved by the appropriate institutional committees and complied with the Guide for the Care and Use of Laboratory Animals (103). Specific details were given in the cited papers. (b) The present paper includes materials originally published in recent reviews and books, particularly in references (1) and (38). The paper offers edited, extended and updated material comparing with the previous publications. Some figures and text fragments are reproduced with the permission. (c) Additional video materials illustrating the experiments described in the paper can be viewed here:

http:/ / people.clarkson.edu/ ekatz / Electrical_snail_2.mov

http:/ / www.newscientist.com/blogs / nstv/2012/06/how-to-hack-a-snail-tocreate-a-living-battery.html

http:/ / www.g4tv.com/videos/58223/ how-to-harvest-electricity-from-lobsters /

\section{DISCLOSURES}

The author declares he has no competing interests as defined by Bioelectronic Medicine, or other interests that might be perceived to influence the results and discussion reported in this paper.

\section{REFERENCES}

1. Katz E. (ed.). (2014) Implantable BioelectronicsDevices, Materials and Applications. Wiley-VCH: Weinheim, Germany. 449 pp.

2. Willner I, Katz E. (eds.) (2005) Bioelectronics: From Theory to Applications. Wiley-VCH: Weinheim, Germany. 475 pp.

3. Pethig RR, Smith S. (2012) Introductory Bioelectronics: For Engineers and Physical Scientists. Wiley: West Sussex, UK. 462 pp.

4. Sarpeshkar R. (2013) Ultra Low Power Bioelectronics: Fundamentals, Biomedical Applications, and BioInspired Systems. Cambridge University Press: Cambridge. 907 pp.

5. Someya T. (ed.) (2013) Stretchable Electronics. Wiley-VCH: Weinheim, Germany. 462 pp.

6. Katz E. (ed.) (2012) Biomolecular Information Processing-From Logic Systems to Smart Sensors and Actuators. Wiley-VCH: Weinheim, Germany. 358 pp.

7. Cai J, et al. (2009) Flexible thick-film electrochem- 
ical sensors: Impact of mechanical bending and stress on the electrochemical behavior. Sens. Actuators B. Chem. 137:379-85.

8. DeMason, C, et al. (2012) Electrophysiological properties of cochlear implantation in the gerbil using a flexible array. Ear Hear. 33:534-42.

9. Hayes DL, Asirvatham SJ, Friedman PA. (eds.) (2013) Cardiac Pacing, Defibrillation and Resynchronization: A Clinical Approach. Wiley-Blackwell: West Sussex, UK. 678 pp.

10. Barold SS, Stroobandt RX, Sinnaeve AF. (2010) Cardiac Pacemakers and Resynchronization Step-byStep. Wiley-Blackwell: Chichester, UK. 480 pp.

11. Zhou D, Greenbaum E. (eds.) (2009) Implantable Neural Prostheses 1: Devices and Applications. Springer: Dordrecht. 383 pp.

12. Hakim NS. (ed.) (2009) Artificial Organs. Springer: London. 200 pp.

13. Philip NS, Carpenter SL, Carpenter LL. (2014) Safe use of repetitive transcranial magnetic stimulation in patients with implanted vagus nerve stimulators. Brain Stimul. 7:608-12.

14. Bauman JA, Ridgway EB, Devinsky O, Doyle WK. (2006) Subpectoral implantation of the vagus nerve stimulator. Neurosurgery. 58:322-5.

15. Huston JM, Tracey KJ. (2011) The pulse of inflammation: heart rate variability, the cholinergic anti-inflammatory pathway and implications for therapy. J. Intern. Med. 269:45-53.

16. Garmo A, Hornsten A, Leksell J. (2013) 'The pump was a saviour for me.' Patients experiences of insulin pump therapy. Diabet. Med. 30:717-23.

17. Ruano G, Bronzino JD, Peterson DR. (eds.) (2014) Personalized Medicine: Principles and Practices. CRC Press: London. 300 pp.

18. Rasmussen MLR, Prause JU, Toft PB. (2010) Eye amputated patients' perspective on life with an artificial eye [abstract]. Acta. Ophthalmol. 88(Suppl s245): 41 .

19. Sue CY, Tsai NC. (2012) Human powered MEMSbased energy harvest devices. Appl. Energy. 93:390-403

20. Yun J, Patel SN, Reynolds MS, Abowd GD. (2011) Design and performance of an optimal inertial power harvester for human-powered. IEEE Trans Mobile Comput. 10:669-83.

21. Nadimi ES, Blanes-Vidal V, Jørgensen RN, Christensen S. (2011) Energy generation for an ad hoc wireless sensor network-based monitoring system using animal head movement. Comput. Electron. Agri. 75:238-42.

22. Reissman T, MacCurdy RB, Garcia E. (2011) Electrical power generation from insect flight. Proc. SPIE. 7977:797702.

23. Delnavaz A, Voix J. (2014) Flexible piezoelectric energy harvesting from jaw movements. Smart Mater. Struct. 23:105020.

24. Jia D, Liu J, Zhou Y. (2009) Harvesting human kinematical energy based on liquid metal magnetohydrodynamics. Phys. Lett A. 373:1305-9.

25. Goudar V, Ren Z, Brochu P, Potkonjak M, Pei QB. (2014) Optimizing the output of a human-powered energy harvesting system with miniaturization and integrated control. IEEE Sensors J. 14:2084-91.

26. Deterre M, Lefeuvre E, Dufour-Gergam E. (2012)

An active piezoelectric energy extraction method for pressure energy harvesting. Smart Mater. Struct. 21:085004

27. Riemer R, Shapiro A. (2011) Biomechanical energy harvesting from human motion: theory, state of the art, design guidelines, and future directions. J. Neuroeng. Rehabil. 8:22.

28. Yang R, Qin Y, Li C, Zhu G, Wang ZL. (2009) Converting biomechanical energy into electricity by a muscle-movement-driven nanogenerator. Nano Lett. 9:1201-5.

29. Rome LC, Flynn L, Goldman EM, Yoo TD. (2005) Generating electricity while walking with loads. Science. 309:1725-8

30. Donelan JM, et al. (2008) Biomechanical energy harvesting: Generating electricity during walking with minimal user effort. Science. 319:807-10.

31. Li Z, Zhu G, Yang R, Wang AC, Wang ZL. (2010) Muscle-driven in vivo nanogenerator. $A d v$. Mater. 22:2534-7.

32. Zurbuchen A, et al. (2013) Energy harvesting from the beating heart by a mass imbalance oscillation generator. Ann. Biomed. Eng. 41:131-41.

33. Sun C, Shi J, Bayerl DJ, Wang X. (2011) PVDF microbelts for harvesting energy from respiration. Energy Environ. Sci. 4:4508-12.

34. Mercier PP, Lysaght AC, Bandyopadhyay S, Chandrakasan AP, Stankovic KM. (2012) Energy extraction from the biologic battery in the inner ear. Nature Biotechnol. 30:1240-5.

35. Hansen BJ, Liu Y, Yang R, Wang ZL. (2010) Hybrid nanogenerator for concurrently harvesting biomechanical and biochemical energy. ACS Nano. 4:3647-52.

36. Schröder U. (2012) From in vitro to in vivobiofuel cells are maturing. Angew. Chem. Int. Ed. 51:7370-2.

37. Falk M, Narváez Villarrubia CW, Babanova S, Atanassov P, Shleev S. (2013) Biofuel cells for biomedical applications: colonizing the animal kingdom. Chemphyschem. 14:2045-58.

38. Katz E, MacVittie K. (2013) Implanted biofuel cells operating in vivo-methods, applications and perspectives-feature article. Energy Environ. Sci. 6:2791-803.

39. Davis F, Higson SPJ. (2007) Biofuel cells—recent advances and applications. Biosens. Bioelectron. 22:1224-35.

40. Cracknell JA, Vincent KA, Armstrong FA. (2008) Enzymes as working or inspirational electrocatalysts for fuel cells and electrolysis. Chem. Rev. 108:2439-61.

41. Luz RAS, Pereira AR, de Souza JCP, Sales FCPF, Crespilho FN. (2014) Enzyme biofuel cells: thermodynamics, kinetics and challenges in applicability. Chemelectrochem. 1:1751-77.

42. Yu EH, Scott K. (2010) Enzymatic biofuel cellsfabrication of enzyme electrodes. Energies. 3:23-42.

43. Meredith MT, Minteer SD. (2012) Biofuel cells: enhanced enzymatic bioelectrocatalysis. Ann.
Rev. Anal. Chem. (Palo Alto Calif.). 5:157-79.

44. Leech D, Kavanagh P, Schuhmann W. (2012) Enzymatic fuel cells: Recent progress. Electrochim. Acta. 84:223-34.

45. Moehlenbrock MJ, Minteer, SD. (2008) Extended lifetime biofuel cells. Chem. Soc. Rev. 37:1188-96.

46. Rincón RA, et al. (2011) Enzymatic fuel cells: integrating flow-through anode and air-breathing cathode into a membrane-less biofuel cell design. Biosens. Bioelectron. 27:132-6.

47. Zhou M, Dong S. (2011) Bioelectrochemical interface engineering: toward the fabrication of electrochemical biosensors, biofuel cells, and self-powered logic biosensors. Acc. Chem. Res. 44:1232-43.

48. Zhang L, et al. (2012) Small-size biofuel cell on paper. Biosens. Bioelectron. 35:155-9.

49. Zhou M, Wang J. (2012) Biofuel cells for selfpowered electrochemical biosensing and logic biosensing: a review. Electroanalysis. 24:197-209.

50. Drake RF, Kusserow BK, Messinger S, Matsuda S. (1970) A tissue implantable fuel cell power supply. Trans. Am. Soc. Artif. Intern. Organs. 16:199-205.

51. Rapoport BI, Kedzierski JT, Sarpeshkar R. (2012) A glucose fuel cell for implantable brain-machine interfaces. PLoS ONE. 7:e38436.

52. Sun MG, et al. (2006) Harnessing the body's own energy and communication resources. IEEE Eng. Med. Biol. Magazine. 25:39-46.

53. Mano N, Mao F, Heller A. (2002) A miniature biofuel cell operating in a physiological buffer. J. Am. Chem. Soc. 124:12962-3.

54. Coman V, et al. (2010) A direct electron transferbased glucose/oxygen biofuel cell operating in human serum. Fuel Cells. 10:9-16.

55. Pan C, et al (2010) Generating electricity from biofluid with a nanowire-based biofuel cell for self-powered nanodevices. Adv. Mater. 22:5388-92.

56. Cosnier S., Le Goff A, Holzinger M. (2014) Towards glucose biofuel cells implanted in human body for powering artificial organs: Review. Electrochem. Commun. 38:19-23.

57. Rasmussen M, Ritzmann RE, Lee I, Pollack AJ, Scherson D. (2012) An implantable biofuel cell for a live insect. J. Am. Chem. Soc. 134:1458-60.

58. Halámková L, et al. (2012) Implanted biofuel cell operating in a living snail. J. Am. Chem. Soc. 134:5040-3.

59. Szczupak A, et al. (2012) Living battery-biofuel cells operating in vivo in clams. Energy Environ. Sci. 5:8891-5.

60. MacVittie K, et al. (2013) From "cyborg" lobsters to a pacemaker powered by implantable biofuel cells. Energy Environ. Sci. 6:81-6.

61. Cinquin P, et al. (2010) A glucose biofuel cell implanted in rats. PLoS ONE. 5:e10476.

62. Sales FC, Iost RM, Martins MV, Almeida MC, Crespilho FN. (2013) An intravenous implantable glucose/dioxygen biofuel cell with modified flexible carbon fiber electrodes. Lab Chip. 13:468-74.

63. Cheng H, et al. (2013) Biofuel cell-based selfpowered biogenerators for online continuous monitoring of neurochemicals in rat brain. Analyst. 138:179-85. 
64. Zebda A, et al. (2013) Single glucose biofuel cells implanted in rats power electronic devices. Sci. Reports. 3:1516.

65. Castorena-Gonzalez JA, et al. (2013) Biofuel cell operating in vivo in rat. Electroanalysis. 25:1579-84.

66. Miyake T, et al. (2011) Enzymatic biofuel cells designed for direct power generation from biofluids in living organisms. Energy Environ. Sci. 4:5008-12.

67. Barton SC, Gallaway J, Atanassov P. (2004) Enzymatic biofuel cells for implantable and microscale devices. Chem. Rev. 104:4867-86.

68. Heller A. (2004) Miniature biofuel cells. Phys. Chem. Chem. Phys. 6:209-16.

69. Mano N, Mao F, Shin W, Chen T, Heller A. (2003) A miniature biofuel cell operating at $0.78 \mathrm{~V}$. Chem. Commun. 518-9.

70. Ieropoulos I, Greenman J, Melhuish C. (2010) Improved energy output levels from small-scale microbial fuel cells. Bioelectrochemistry. 78:44-50.

71. Ieropoulos I, Greenman J, Melhuish C. (2008) Microbial fuel cells based on carbon veil electrodes: Stack configuration and scalability. Int. J. Energy Res. 32:1228-40.

72. Aelterman P, Rabaey K, Pham HT, Boon N, Verstraete W. (2006) Continuous electricity generation at high voltages and currents using stacked microbial fuel cells. Environ. Sci. Technol. 40:3388-94.

73. Meehan A, Ga, H, Lewandowski Z. (2011) Energy harvesting with microbial fuel cell and power management system. IEEE Trans. Power Electronics. 26:176-81.

74. How To Harvest Electricity From Lobsters [online video]. Los Angeles: G4 Media Inc.; 2012 Apr 18. Available from: http:/ / www.g4tv.com/videos/58223/howto-harvest-electricity-from-lobsters /

75. Hanashi T, et al. (2009) BioCapacitor-a novel category of biosensor. Biosens. Bioelectron. 24:1837-42.

76. Hanashi T, Yamazaki T, Tsugawa W, Ikebukuro K, Sode K. (2011) BioRadioTransmitter: a self-powered wireless glucose-sensing system. J. Diabetes Sci. Technol. 5:1030-5.

77. Falk M, et al. (2014) Self-powered wireless carbohydrate/oxygen sensitive biodevice based on radio signal transmission. PlosOne. 9:e109104.

78. Pan F, Samaddar T. (2006) Charge Pump Circuit Design. McGraw-Hill Professional: New York. 247 pp.

79. Southcott M, et al. (2013) Pacemaker powered by implantable biofuel cell operating under conditions mimicking human blood circulation system-battery not included. Phys. Chem. Chem. Phys. 15:6278-83.

80. Kusumoto F, Goldschlager N. (2010) Remote monitoring of patients with implanted cardiac devices. Clin. Cardiology. 33:10-7.

81. Kjeang E, Djilali N, Sinton D. (2009) Microfluidic fuel cells: a review. J. Power Sources. 186:353-69.

82. Jia W, et al. (2013) Electrochemical tattoo biosensors for real-time noninvasive lactate monitoring in human perspiration. Anal. Chem. 85:6553-60.

83. Jia WZ, Valdes-Ramirez G, Bandodkar AJ, Windmiller JR, Wang J. (2013) Epidermal biofuel cells:
Energy harvesting from human perspiration. Angew. Chem. Int. Ed. 52:7233-6.

84. MacVittie K, Conlon T, Katz E. (2014) A wireless transmission system powered by an enzyme biofuel cell implanted in an orange. Bioelectrochemistry. 2014, Nov 5 [Epub ahead of print].

85. Oncescu V, Erickson D. (2013) High volumetric power density, non-enzymatic, glucose fuel cells. Sci. Reports 3:1226.

86. Kerzenmacher S, Schroeder M, Brämer R, Zengerle R, von Stetten F. (2010) Raney-platinum film electrodes for potentially implantable glucose fuel cells. Part 1: Nickel-free glucose oxidation anodes. J. Power Sources. 195:6516-23.

87. Kerzenmacher S, et al. (2010) Raney-platinum film electrodes for potentially implantable glucose fuel cells. Part 2: Glucose-tolerant oxygen reduction cathodes. J. Power Sources. 195:6524-31.

88. Yan X, Ge X, Cui S. (2011) Pt-decorated nanoporous gold for glucose electrooxidation in neutral and alkaline solutions. Nanoscale Res. Lett. 6:313.

89. Slaughter G, Sunday J. (2014) A membraneless single compartment abiotic glucose fuel cell. J. Power Sources. 261:332-6.

90. Du J, Catania C, Bazan GC. (2014) Modification of abiotic-biotic interfaces with small molecules and nanomaterials for improved bioelectronics. Chem. Mater. 26:686-97.

91. Kerzenmacher S, Ducrée J, Zengerle R, von Stetten F. (2008) Energy harvesting by implantable abiotically catalyzed glucose fuel cells. J. Power Sources. 182:1-17.

92. Kerzenmacher S, Ducrée J, Zengerle R, von Stetten F. (2008) An abiotically catalyzed glucose fuel cell for powering medical implants: Reconstructed manufacturing protocol and analysis of performance. J. Power Sources. 182:66-75.

93. Kloke A, et al. (2011) A single layer glucose fuel cell intended as power supplying coating for medical implants. Fuel Cells. 11:316-26.

94. Oncescu V, Erickson D. (2011) A microfabricated low cost enzyme-free glucose fuel cell for powering low-power implantable devices. J. Power Sources. 196:9169-75.

95. Kerzenmacher S, Kräling U, Metz T, Zengerle R, von Stetten F. (2011) A potentially implantable glucose fuel cell with Raney-platinum film electrodes for improved hydrolytic and oxidative stability. J. Power Sources 196:1264-72.

96. Sharma T, et al. (2011) Mesoporous silica as a membrane for ultra-thin implantable direct glucose fuel cells. Lab Chip. 11:2460-5.

97. Kerzenmacher S, Rubenwolf S, Kloke A, Zengerle R, Gescher J. (2010) Biofuel cells for the energy supply of distributed systems: State-of-the-Art and applications. In: Sensoren und Messsysteme 2010; 2010 May 18-19; Nürnberg, Germany. p. 562-5. Paper 100.

98. Kerzenmacher S, et al. (2008) An efficient lowpower DC-DC converter enables operation of a cardiac pacemaker by an integrated glucose fuel cell. In: [Proceedings of] PowerMEMS $2008+$ microEMS2008; 2008 Nov 9-12; Sendai, Japan. p. 189-92.
99. Marks WJ Jr. (ed.). (2010) Deep Brain Stimulation Management. Cambridge University Press, Cambridge. $167 \mathrm{pp}$.

100. Kreis P, Fishman S. (2009) Spinal Cord Stimulation Implantation: Percutaneous Implantation Techniques. Oxford University Press: USA. 153 pp.

101. Johnson FE, Virgo KS. (eds.) (2006) The Bionic Human: Health Promotion for People with Implanted Prosthetic Devices. Humana Press, Totowa, NJ. 704 pp.

102. Giselbrecht S, Rapp BE, Niemeyer CM. (2013) The chemistry of cyborgs-interfacing technical devices with organisms. Angew. Chem. Int. Ed. 52:13942-57.

103. Committee for the Update of the Guide for the Care and Use of Laboratory Animals, Institute for Laboratory Animal Research, Division on Earth and Life Studies, National Research Council of the National Academies. (2011) Guide for the Care and Use of Laboratory Animals. 8th edition. Washington (DC): National Academies Press.

Cite this article as: Katz E. (2015) Implantable biofuel cells operating in vivo-potential power sources for bioelectronic devices. Bioelectron. Med. 2:1-12. 